OPEN ACCESS

Edited by:

Konstantin Loganovsky,

National Academy of Medical Science

of Ukraine, Ukraine

Reviewed by:

Maria Teresa Avella,

University of Pisa, Italy

Batul Hanife,

Azienda Provinciale per i Servizi

Sanitari, Italy

*Correspondence:

Paolo Cianconi

pcianco@gmail.com

Specialty section:

This article was submitted to

Public Mental Health,

a section of the journal

Frontiers in Psychiatry

Received: 07 August 2019

Accepted: 28 January 2020

Published: 06 March 2020

Citation:

Cianconi P, Betrò S and Janiri L (2020)

The Impact of Climate Change on

Mental Health: A Systematic

Descriptive Review.

Front. Psychiatry 11:74.

doi: 10.3389/fpsyt.2020.00074

\section{The Impact of Climate Change on Mental Health: A Systematic Descriptive Review}

\author{
Paolo Cianconi $^{1 *}$, Sophia Betrò ${ }^{2}$ and Luigi Janiri ${ }^{1,3}$ \\ ${ }^{1}$ Department of Neurosciences, Institute of Psychiatry, Catholic University, Rome, Italy, ${ }^{2}$ Institute of Psychopathology, Rome, \\ Italy, ${ }^{3}$ Fondazione Policlinico Universitario A. Gemelli, IRCCS, Rome, Italy
}

Background: Climate change is one of the great challenges of our time. The consequences of climate change on exposed biological subjects, as well as on vulnerable societies, are a concern for the entire scientific community. Rising temperatures, heat waves, floods, tornadoes, hurricanes, droughts, fires, loss of forest, and glaciers, along with disappearance of rivers and desertification, can directly and indirectly cause human pathologies that are physical and mental. However, there is a clear lack in psychiatric studies on mental disorders linked to climate change.

Methods: Literature available on PubMed, EMBASE, and Cochrane library until end of June 2019 were reviewed. The total number of articles and association reports was 445. From these, 163 were selected. We looked for the association between classical psychiatric disorders such as anxiety schizophrenia, mood disorder and depression, suicide, aggressive behaviors, despair for the loss of usual landscape, and phenomena related to climate change and extreme weather. Review of literature was then divided into specific areas: the course of change in mental health, temperature, water, air pollution, drought, as well as the exposure of certain groups and critical psychological adaptations.

Results: Climate change has an impact on a large part of the population, in different geographical areas and with different types of threats to public health. However, the delay in studies on climate change and mental health consequences is an important aspect. Lack of literature is perhaps due to the complexity and novelty of this issue. It has been shown that climate change acts on mental health with different timing. The phenomenology of the effects of climate change differs greatly-some mental disorders are common and others more specific in relation to atypical climatic conditions. Moreover, climate change also affects different population groups who are directly exposed and more vulnerable in their geographical conditions, as well as a lack of access to resources, information, and protection. Perhaps it is also worth underlining that in some papers the connection between climatic events and mental disorders was described through the introduction of new terms, coined only recently: ecoanxiety, ecoguilt, ecopsychology, ecological grief, solastalgia, biospheric concern, etc.

Conclusions: The effects of climate change can be direct or indirect, short-term or longterm. Acute events can act through mechanisms similar to that of traumatic stress, leading 
to well-understood psychopathological patterns. In addition, the consequences of exposure to extreme or prolonged weather-related events can also be delayed, encompassing disorders such as posttraumatic stress, or even transmitted to later generations.

Keywords: climate change, mental health, resilience, migration, vulnerability, climatic and economic turmoil, extreme events

\section{INTRODUCTION}

Since the 1970's scientists have been trying to understand processes related to environmental factors that lead to climate change. Our climate is changing, with an unequivocal regional effect such as heath waves, floods, and droughts. Human activities have altered the atmospheric composition, producing a greenhouse effect leading to global warming. These activities produce a flux of complex variance with setbacks related also to mental health (1). Scientists argue that they still have to understand what kind of transformations can be expected depending on the temperature, how pervasive theses transformations will be in the various environments, when and what points of no return can be identified, which short and longterm consequences may be foreseen, and who are the most exposed biological subjects and most vulnerable societies. A part of climate change is due to the conditions of the planet that are independent of human activities (solar irradiance, autonomous activity of the planet such volcanic eruptions). Most studies are focus on the chain of events occurring in the biosphere primarily due to global warming. Global warming is in part attributable to the anthropogenic activity through the use of fossil fuels, deforestation, and pollution (1).

Global warming is likely to cause widespread emergencies in the future (2). These emergencies are real phenomena when extreme climatic events have an impact on local territories. These events are: extreme heat (increased global mean surface temperature, heat waves); climate change-related water disasters (CCRWDs) (sea level (3)-flooding, hurricanes, and coastal storms); droughts; wildfires; winter storms, extreme snow, and severe CAPE (convective available potential energy) thunderstorms (4) (supercells, derechos, and tornados).

When can we consider a climatic event as "extreme"? In science, the term "extreme" is used in several contexts. By definition, "extremes" are events that are rare or outside the normal range. A definition of extreme has been already deeply discussed in Seneviratne et al. report (5). Devastating natural weather phenomena are not exclusively caused by climate change. Some seasonal change or annual means temperature may be "extreme". Therefore, extremes are understood within the context in which they take place. People and communities judge events as "extreme" by comparing them with personal experiences, when these events are unprecedented or divergent from previous phenomena (6). In the area affected by sudden and extreme climatic events, it is not rare to hear from the elderly that "nothing like this has ever happened". However, focusing on a single climatic extreme and extraordinarily event does not allow to understand the bigger picture. Nonetheless, recently extremes are becoming more evident, even when a longer time arc is considered.

All weather events are affected by climate change. Higher global temperatures and differences in humidity compared to previous eras have been registered in recent years (6). There is some degree of uncertainty regarding climate change and the scientific community has not yet been able to fully link climate change to the increase of extreme weather events (7). However, many authors strongly believe extreme climatic events have important influence on ecosystems and societies. Shifts and trends of mean temperatures and precipitation have been directly correlated to the increases of hurricanes, droughts, heat waves, and heavy precipitation (8). Scholars have confidence that the anthropogenic influence has contributed to the increase of extreme events with disastrous outcomes on global scale (9).

The Katowice Climate Change Conference, held in Poland at the end of 2018, was the last conference concerning global change in an effort to commit each state to reduce emissions, trying to keep the global temperature change below $1.5^{\circ} \mathrm{C}$. An increase of average global temperature over $1.5^{\circ} \mathrm{C}$ has been linked to a global rise in the frequency and intensity of extreme weather events $(10,11)$. Moreover, the greenhouse effect has already altered global climate dynamics (12). A vast amount of information supports that anthropogenic activity is responsible for extreme events, such as the heat waves in Europe and Russia (13), and the devastating floods in Pakistan $(14,15)$. Understanding how climate change relates to extreme events is a current scientific challenge. There are different explanatory experimental models (16). Each method must be able to explain the consequences of human activity and how they are linked to natural climatic variations.

Models on how global climate has evolved throughout the eras can be useful in order to give a context to current extreme events $(17,18)$. Such studies have increased over the past decades. Historical models and earth surface temperature readouts suggest that there is a strong connection between anthropogenic warming and the increased persistence of extreme weather (14). These approaches allow us to quantify the influence of historical global warming on the probability and the severity of individual events (19). All extreme climatic events are associated with large scale changes in the thermodynamic environments (12). For example, increases of mean temperature lead to heat waves (20); decreases in ground humidity and higher evaporation trends lead to higher incidence and severity of droughts (21) or changes in soil-moisture (22); high sea 
surface temperature and anomalies in humidity are linked to storms and the melting of Arctic ice fields (23).

Statistical methods link extremes to an observed climatic trend. This has proven to be challenging. The satellite era (1979-present) coincides with a rapid increase of Arctic surface temperatures. There is a high statistical confidence that links the anthropogenic action to the current minimum extension reached by Arctic glaciers, caused by the alteration of atmospheric circulation, atmospheric humidity, and thermodynamic factors in general (24). Authors strongly believe that some types of extreme event, most notably heat waves and precipitation extremes, will increase as an effect of the global warming (25). The frequency and the intensity of extreme climate events are unprecedented in global history (2). The debate is still open and, despite substantial progresses, achieving an accurate analysis of local events, evaluating all the involved thermodynamic processes, has proven to be difficult (24). Some studies already suggest that a more complex mechanisms may be involved in unprecedented extremes climate events (25).

However, our climate does not act as a linear system (26), but rather as a complex system (27), characterized by regime shifts, oscillations, and chaotic fluctuations in all timescales (26), so that predictions are impervious. Climate change will inevitably impose alterations in our lifestyles and consequences in terms of human losses and social readjustments. That said, it is not clear how many people on the planet will be affected by extreme phenomena caused by climate change, and to what extent and when these phenomena will compromise the quality of their life. People could be at risk for their survival, either directly (during, for example, an extreme event) or indirectly (reduction of food, famine, water scarcity, decrease in places to cultivate or hunt, displacement). In order to advise societies on how to cope and adapt to these phenomena, specialized international agencies have produced reports on climate change and the extreme events suggesting strategies and remedies $(9,28)$. Climatology, once a sub-field of physical geography, has now grown in relevance throughout the scientific community. Extreme events are the point of interaction between climate change and the human world (29).

Moreover, our ecosystem will face plant and animal extinction due to failure to adapt or migrate (30) leading to an increased risk of an "extinction domino effect" (31). Climate change can redistribute the strength of ecological interactions between predator and prey (32). Moreover, effects of global warming such as droughts and soil dry out (33) could have amplified effect especially in rural areas (34) such as difficulties in farming, starvation, forced migration (35); the consequent overcrowding of coastal and delta areas could also lead to physical illness by vector-borne disease. Global warming could pose a risk to ecosystems with decreased biodiversity, modifying fishing, and hunting activities (36). Famines can also be caused by abnormal insects' populations and consequent increased use of pesticide or GMOs (37) with a change in biodiversity. Eighty percent of global population is affected by water and food insecurity due to climate change effects (38).

Environmental factors are becoming increasingly important in psychiatry due to the fact that they can induce congenital defects, impair neurodevelopment, even trigger endogenous mental disorders as well arouse psychosomatic and neurological disorders (39). Climate can produce strong phenomena with a disastrous impact among human societies. Disasters create a different kind of psychological and psychopathological distress compared to normal seasonal weather changes, as seen in tornados, floods, and droughts. Furthermore, other climatic events, usually overlooked in studies on mental health of exposed populations (e.g. ocean acidification, acid rain, superfog (40), glacier melting, biomass extinction), could also have a broader impact on mental health.

Psychiatry has only recently begun to deal with climate change, albeit specific literature concerning the climate events in relation to psychiatric disorders is still lacking and rather undefined (41-43).

\section{MATERIALS AND METHODS}

All papers available on PubMed, EMBASE, and Cochrane published from 1996 until June 2019 were reviewed. Searched terms included "PTSD" or "anxiety" or "depression" or "mental health" or "psychiatric disorder" or "psychosis" or "schizophrenia" or "suicide" or "mood disorder" combined with "climate change" or "extreme events" or "disaster events" or "surface air temperature" or "heath waves" or "rise temperature" or "floods" or "flooding" or "increased waters" or "hurricanes" or "tornado" or "drought" or "wildfires" or "vector borne disease" or "deglaciation" or "deforestation" or "river disappearance" or "increased of desert" or "extinction" or "solastalgia" or "ecoanxiety" or "ecomigration" or "resilience" or "adaptation". The search included all languages and we focus on articles written in English or Italian. Studies related to both human and animal conditions were selected, including data available from government and non-governmental organizations, reports, and books.

Screening was made on the basis of abstract and title. Exclusion criteria are:

- Even in the event that direct effect on mental health was proven, articles on urbanization $(\mathrm{n}=3)$, air and water pollution $(n=66)$, chemical pollution $(n=7)$, and ionizing radiation $(n=22)$ were excluded, insofar as they were not directly related to the focus of our study.

- Articles dealing exclusively with transmission of infectious diseases $(n=3)$ or physical-medical pathologies were excluded.

The following articles was eligible for analysis based on their specific topic. Exclusions $(n=178)$ were made in order to avoid redundancy of cited material (Figure 1).

- 100 articles on climate change in general-34 articles were selected;

- 18 articles on heat waves and temperature increase-six articles on heat waves and seven on temperature increase were selected; 


\section{PRISMA 2009 Flow Diagram}

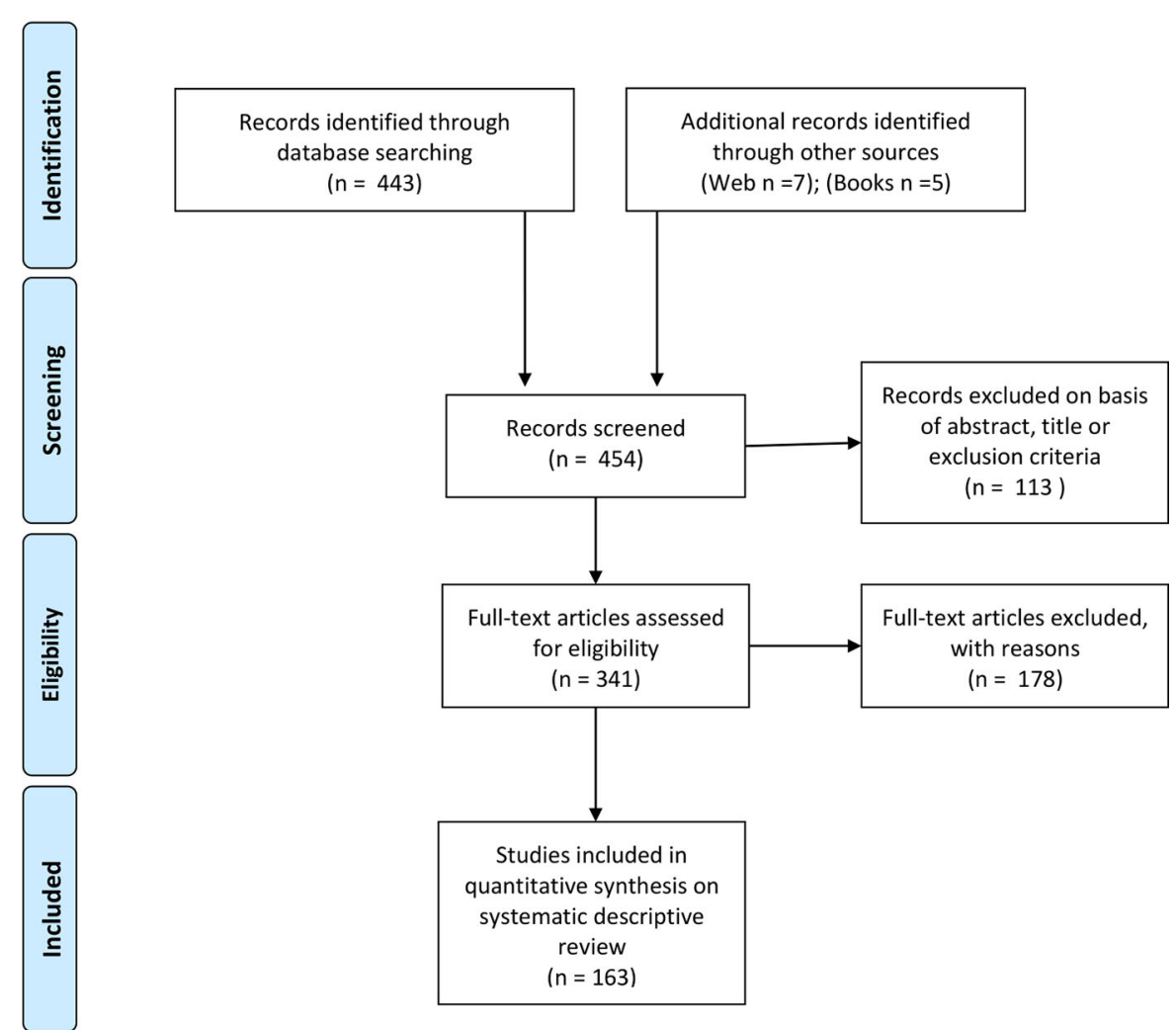

FIGURE 1 | PRISMA flow diagram.

- 31 articles on flooding and sea-level increase-20 were selected on flooding and 6 on sea-level increase;

- 20 articles on hurricanes-13 were included in this research;

- 10 articles on deforestation-seven were selected;

- 18 articles on drought-15 were selected;

- 25 articles on indigenous communities, vulnerability, and migration-18 were selected;

- 23 articles on economic impact-two were selected;

- 16 articles on wildfires-10 articles were selected;

- 84 articles on psychiatric disorders connected with global climate change-27 general articles were selected. Moreover, 28 association reports (WHO; IPCC; APA etc.) were studied -15 reports were selected.

In each category, only pivotal studies included in the range of the publication years were selected.

A total of 97 articles were analyzed, covering various extreme weather events and their effects on psychiatric illness. We examined
7 reports and 28 reviews; among these, 3 were about communities, 1 about migrations; one studied event and consequences in 157 countries, one summarized the interviews performed on 105,549 patients. We analyzed 8 articles with regression time studies (concerning 29 countries and data about surveys performed on 1,9 million citizens). Authors of 14 articles have given self-reported questionnaires or surveys (range of scrutinized results went from 30 to 381,916 people in internet questionnaires). Nine articles reported results from interviews, mainly about communities and children studies, ranging from 14 to 342 people interviewed. One of the selected articles is a population based retrospective study with 9 million data collected; one experimental study use statistic to analyze 344,957 twitters, another analyzed 600 million social media updates and reactions for a longitudinal and country scale evidence study. Four of the selected articles were case-studies with 17 people interviewed and 1,526 questionnaires completed. Excluding other minor selected categorized, other articles were longitudinal or cross-sectional studies. 


\section{RESULTS}

\section{Course of Mental Health Changes Following Extreme Events}

A vast body of works on mental health and climate change is now emerging $(43,44)$. Impacts on mental health can occur after or even before an extreme event (45). Mental health outcomes of climate change range from minimal stress and distress symptoms to clinical disorders, ranging from anxiety and sleep disturbances (46) to depression, post-traumatic stress, and suicidal thoughts $(10,47)$. Other consequences might include the effect on individuals and communities in their everyday life, perceptions, and experiences, having to cope, understand, and respond appropriately to climate change and its implications (10). A large number of people exposed to climate or weather-related natural disasters experience stress and serious mental health consequences. Some natural disasters are possibly going to be more frequent because of climate change. Notoriously, reactions to extreme events that involve life disruption, such as loss of life, resources, social support and social networks, or extensive relocation, are posttraumatic stress disorder (PTSD), depression, and general anxiety, increased substance use or misuse, and suicidal thoughts (48). Research has shown that peritraumatic experience is highly related to acute stress during and immediately after a disaster, which is expected to lead to the onset of PTSD (49). Later on, other consequences come out for survivors, such as reduced daily life activities and the loss of their "sense of place". These conditions could have an impact and exacerbate mental health risks. News regarding climate change makes people uncertain and stressed, even depressed and with a sense of powerlessness. The concrete impact of those changes in life brings different types of psychopathological reaction to these events. Briefly, acute impacts refer to all the extreme events (e.g. floods, hurricanes, wildfires, etc.) that immediately expose undefended and helpless people to mental injuries. Subacute impacts involve intense emotions experienced by people who indirectly witness the effects of climate change, anxiety related to uncertainty about surviving of humans and other species and, finally, sense of being blocked, disorientation, and passivity. Long-term outcomes come in the form of large-scale social and community effects outbreaking into forms of violence, struggle over limited resources, displacement and forced migration $(35,50)$, post-disaster adjustment, and chronic environmental stress (51). In our study we considered the consequences for mental health for each single extreme event. We also considered mental health adaptation to environment changes.

\section{Heat Waves}

As a part of the Climate and Health Profile Report, both direct and indirect impact on health with regard to extreme heat and extreme precipitation were identified. Health risks caused by these factors has significantly risen in recent years (52). Heat weaves are spikes of high temperatures lasting some days that range outside the normal temperature for a specific season (20). This phenomenon is connected with climate change as they have increased in frequency and intensity. Moreover, the frequency and intensity of heat waves are considered extreme events linked to climate change, with a regional effect.

Physical health, mental health, human well-being, and heat waves appear to be specifically interconnected. Heat stress directly caused by heat waves has been associated with mood disorders, anxiety, and related consequences (53). People with mental illness were three times more likely to run the risk of death from a heat wave than those without mental illness (45). During pregnancy, especially in the second and third trimester, exposure to heat waves has been showed to be related to a lower average birth weight and increase of incidence of preterm birth. Effects during childhood and adulthood comprised reduced schooling and economic activity, other than behavioral and motor problems and reduced IQ (45). Some evidence seems to hint a different vulnerability between genders. The percentage of deaths were higher in women than men during the European heat wave. Negative outcomes of heat waves are also related to social factors. Women, young people, and people with low socioeconomic status have shown to be more vulnerable to anxiety and mood disorders related to disasters (54). Heatrelated illnesses and waterborne diseases are also connected (52). It could also be noted that people are outside more during the summer, and this could increase the opportunity for conflicts. In hot temperatures, increase in discomfort leads to increase feelings of hostility and aggressive thoughts and possibly actions. Hotter cities were more violent than cooler cities. The increase in heat-related violence are greater in hot summers and showed increased rates in hotter years (55). Indeed, being exposed to extreme heat can lead to physical and psychological fatigue (53)-there is a clear association between warming temperatures and rising suicide rates, especially in an early summer 'peak' (56). Alcohol is likely to be involved in increasing aggression. Higher temperatures than usual, especially in June and July, were associated with an outbreak of aggressive crimes. The co-occurrence of hot summer days and weekends is therefore a perfect mix, resulting in a massive increase in shootings (57). Preventive measures should be taken against extreme temperatures to protect health, planning targeted public health monitoring, expanding the availability of air conditioning and providing countermeasures for what is known as the "urban heat island" effect (52).

\section{Water}

Global warming will lead to CCRWDs such as an increase in both intensity and global number of tropical cyclones $(58,59)$, frequency and severity of hurricanes, and flooding (60).

\section{Floods}

Floods are an overflow of water, usually from the ocean, submerging land areas. Flooding is one of the most frequent types of major disaster, leading to 53,000 deaths in the past decade (61). CCRWDs generate flooding in urban areas on the coasts, like those in Asian deltas rivers $(62,63)$. These events could potentially have a negative effect on the health of vulnerable populations. Moreover, CCRWDs have a devastating impact on communities and the health of 
residents, for example by exposing people to toxins, precipitating population susceptibility, and creating crises for healthcare infrastructures (60). There are direct impacts in terms of morbidity and mortality related to water (such as drowning, electrocution, cardiovascular events, nonfatal injuries, and exacerbation of chronic illness); waterborne diseases (due to contamination of drinking water); infectious diseases (64); and psychiatric and mental health disorders. The principal effect after flooding seems to be located in the mental health area, leading especially to PTSD. A direct correlation between the intensity of the disaster and the severity of the mental health effects was noted (65). After the acute emergency phase, a number of members of the affected populations are subjected to some level of psychological distress and mental health problems (61). As studied all around the world (i.e. India and Bangladesh (61); Dakota USA (66); Italy (67); Venezuela (68) etc.) floods bring mourning, displacement, and psychosocial stress due to loss of lives and belongings, as a direct outcome of the disaster or of its consequences. All these are risk factors for PTSD, depression, and anxiety (69). With specific reference to flood victims, $20 \%$ had been diagnosed with depression, 28.3\% with anxiety and 36\% with PTSD (70). Consequences are still present well after the flood is over, due to the presence of mourning, economic problems, and behavioral problems in children $(71,72)$. Moreover, some cases show an increase in substance abuse, domestic violence, as the calamity exacerbates and precipitates previous existing people's mental health problems $(70,73-75)$. Contradictory evidence was obtained regarding suicide following a flooding. In addiction there are aspects of vulnerability such as poverty $(60,76)$, living in makeshift housing solutions, and the lack of access to healthcare. Flooding disrupts infrastructure, causing problems for the standard systems of care, including mental health care that could assist and mitigate the psychological outcome for victims. Other susceptibility factors for mental illness related to these events include: women, the young or elderly age, having a disability, being part of an ethnic or linguistic minority, living in a household with a female head and having lower level of schooling. Among residents and relief workers, having limited resources or living in lower income countries are additional risk factors (77). The disaster can only exacerbate any existing barriers in the access of mental health care in the population (78). The focus of many articles is on PTSD occurring immediately after the disaster, when vulnerable people are more at risk and fragile (61). This part of the population can develop mental health problems and mental disorders in the short-, medium- or long-term (78). In addition, even families not residing nearby the affected area shown high levels of post-traumatic stress, due to the fact that they still bear the charge of the disruption of community cohesion (76). People who are affected by flooding could show remarkable resilience, however they still need organizations to support them, in order to recognize and cope with the distress, while also providing assistance to avoid any possible additional mental health problem or disorder arising from the situation. Psychosocial resilience, due to its personal and collective components, makes it fundamental to mitigate the distress of flooding together with the social and health risks caused by the event. Restoring social cohesion of communities and families immediately after calamities is crucial in order to reduce suffering and promote effective recovery (73). Community resilience also has a preventive effect, as it prepares the population for future events while also helping them to cope with the current situation (76).

\section{Air}

Tornadoes, hurricanes, and storms have all increased in intensity, frequency, and duration over recent decades. Data on tornadoes and mental health issues came from the latest kind of this disasters, such as hurricane Katrina in Florida and Louisiana in 2005 and Sandy in 2012 in Cuba, Jamaica, and Haiti (79-81). There is still uncertainty regarding how much humanity is at fault for this increase (82). Based on information provided by the United Nations Development Program, nations like the United States, Japan, Australia, and New Zealand and other twenty-nine developing nations have been greatly exposed to hurricanes, cyclones, and typhoons (83). The damage suffered by health care infrastructure and the interruption of public health service due to hurricanes leads to an increase in serious illness, injuries, disability, and death (84). As in extreme events, there are health issues that emerged or worsened after hurricanes due to psychological stress: increase in rates of cardiovascular diseases (85), prenatal maternal stress and depression, infants more likely to experience anxiety, fear and sadness, and less responsive to pleasant stimuli (86), lack of insurance possibly increasing chronic illnesses with no access to medical care during a disaster $(87,88)$, population exposures to contaminated floodwaters (88). Many people experienced PTSD, stress, depression, anxiety (87), and suicide (79). Consequences of material damages lead to substance abuse $(45,89)$. The incidence of PTSD, that has been studied most extensively, was consistently associated with several factors. Severity of exposure and previous mental health problems has shown to be stable predictors of development of distress (84). Other vulnerability factors are represented by: age, women, low education level, low socioeconomic status, being unemployed or disabled before hurricane disaster, and being single (54). People living in an affected area showed high levels of suicide and suicidal ideation, one in six people developed PTSD, and half of them developed an anxiety or mood disorder, including depression (45). Additional consequences are the loss of social support, job insecurity, and loss of belongings, as well as disruption of medical health system, displacement, and relocation are related to the onset of psychological distress. Mental health disorders are often seen even one year after the disaster or event (90). A strategy for coping immediately after a hurricane is a successful evacuation of vulnerable areas by reducing the number of victims. Displacement to shelters often results in separation from social support networks and creates a disruption in normal psychological processes, particularly familiarity, attachment and identity, and decrease in perceived social support in the months following the hurricane, which in turn has been shown to be associated with increased symptoms of general psychological distress. Being moved from one shelter to another is traumatic, compounded by the limited amount of healthcare services (91). 


\section{Drought}

Historically, a natural drought lasts about a decade. Due to climate change, there will be droughts lasting around three decades, also known as "megadroughts". From a current historical frequency of $12 \%$, these events may increase up to $60 \%$ (92) due to possible changes in future anthropogenic greenhouse gas emissions and atmospheric concentrations measured in CO2-equivalents (93). A combination of high temperatures and low precipitation increases the frequency of drought over the world (94). A temperature fluctuation is correlated with agricultural loss by affecting crop productivity and yields. This loss is linked to a decrease on economic growth leading to a long-term economic disadvantage and promoting political instability and conflicts (95). Farmers all over the world are more vulnerable to environment-induced mental health risks carried by drought. Long-term droughts and erratic rain fall have been associated with deterioration of economic conditions, reduced social functioning, and psychological distance to perception of negative climatic conditions (96). The regulation and adjustment of emotion is disrupted by depression, demoralization, fatalism, passively resigning to fate, especially in women and adolescents or people with lower socioeconomic status, showing feelings of distress and helplessness $(52,53)$. Drought has been often connected to suicide (97-101), especially in older people (102). In semi-arid and peri-urban areas, adaptive capacity is necessary to cope with an increased temperature and a reduced rainfall. In this case, vulnerability is seen as the degree to which people are susceptible by events that disrupt their lives-events that are beyond their control. Resilient systems cope with extreme events in order to create a response that maintains essential function, identity, and structure, and the capacity for adaptation. Consequently, local communities strongly perceive the impact of climate change. Negative events stimulate feelings of alertness, constant monitoring of current and future events, mental distress, anxiety, depression, and suicide (103), as well as prolonged emotional stress, inevitably provoking high job insecurity (51) and other psychological issues (104).

Drought and migration are related through an assessment of crop yields (105). The landscape changes with periodical drought impact for example on the Turkana's ability to gain access food, water, health, and security. These indigenous people are farmers that have grown dramatically in number in the last decades with a majority living below the poverty line. Prolonged and more frequent droughts and unpredictable rainy seasons have exacerbated the difficult access to potable water or food. Consequently, changes in water availability, temperature or other environmental variables can have a truly devastating impact on their daily life. Many extreme weather events and famine lead to displacement of entire communities and forced migration, within and outside national borders, with onset on conflicts over natural resources (106). In northern Ghana's savanna (an arid zone with severe droughts), climate change exposes farmers to adverse climatic conditions that include low rainfall, forest fires, soil erosion, loss of soil fertility, poor harvest, and destruction of property and livestock. In this region, farmers with small plots are at a higher risk of suffering acute, sub-acute, and long-term problems caused by extreme climate change (51).

\section{Wildfires}

The term "wildfire" refers to large-scale fires, generally occurring in forests and jungles. These phenomena have involved Siberia, Central Africa, and the Amazon in the present times. The areas affected by the wildfire may be sparsely populated or nearby the city boundaries. The greatest concerns are those related to the climate. The effects on the ecosystem are devastating, as a forest's carbon dioxide storage capacity is forever lost (107). Once burnt, forest tend to become savannah, scarcely covered by deciduous trees or cultivation. Vast decline of forests will have reverberations for the world's climate, as anticipated by many government administrations and institutions all over the world. A "business as usual" scenario will lead to a rise in temperature of about 4 degrees Celsius by 2100 and plants will have to find new strategies to survive.

In the past, a more local phenomenon has been described as bush-fire. These involved urban areas in proximity with bushlands or forests and could affect residential neighborhoods, suburbs or slums in different ways, albeit devastating for farmers and people in the area. Firestorms generated by bush-fires led to destruction and evacuation of residents. Wildfires have a heterogeneous impact on property damage, physical injuries, and mental health (108). During the years following the disaster, an increase of mental health issues was observed, such as general mental health problems, post traumatic disorders (109), psychosomatic illness, and alcohol abuse (110). Effects can be delayed in onset and can persist over at least several years. Proximal populations, not directly affected by the bush-fires, can also be involved (111). Studies performed in areas hit by Australian bush-fires observed that a year after the events $42 \%$ of the population exposed was classified as potential psychiatric cases (109). Californian wildfires also offer a rather dramatic picture, with $33 \%$ showing symptoms of major depression and $24 \%$ showing symptoms of PTSD. A similar effect was observed in Greek wildfires (112), with an increased somatization symptoms, depression, anxiety, hostility, and paranoia (113). Post-disaster mental health issues observed were PTSD, physiological hyperarousal, chronic dissociation, sadness and depression, detachment (114) disorganized thinking and behavior, numbing or avoidance, poor concentration, and behavioral problems. In the youth population, connections have been found between the young age and the experience of personal life threat (115). Children were also affected by bush-fires, showing posttraumatic phenomena such as anxiety disorders and panic attacks, problems sleeping, acute stress disorder, compulsively repetitive play, flashbacks, and psychotic disorders (116).

Wildfires could become quite frequent with climate change. Addressing such phenomena on a global scale will prove challenging. It is also difficult to predict how populations will react once the anthropogenic role of this type of event takes hold. 


\section{Long-Term Environment Changes and Critical Psychological Adaptations}

Climate change leads to extreme events that bring an immediate and direct impact on the population in terms of mental health. However, changes also occur slowly, as in the case of temperature increase. Climate change will also modify the representation of territories as historically and traditionally known and lived by the populations. This loss of spatial and cultural parameters is not favorable to the people's life in terms of changes of lifestyle that they might undergo. People may also become less familiar with places and usual products (resources) of the environment. Landscape changes are brought about by deforestation, deglaciation, river disappearance, desertification, water shortage, increase of infectious diseases, and biomass extinction. On its own, desertification (117) may cause resource-based conflicts (106).

\section{Increase of Average Land Surface Air Temperature}

The earth could become very hot due to the anthropogenic effect of greenhouse gases that alters the dynamics of CO2. Moreover, recent studies have highlighted how climate change and global warming are nonlinear trends (118).

The increase in environmental temperature can notoriously compromise the functioning of the central nervous system, similar to insolation and heat stroke. The correct temperature for proper functioning is around $22^{\circ} \mathrm{C}$ (119). Outside temperature can affect the risk of onset or continuous mental disorders in different ways. For example, temperature stress can influence psycho-physiological functions by directly affecting bio-chemicals levels, (e.g. altering the production of serotonin and dopamine) (120) or by disrupting the homeostasis of thermoregulation $(121,122)$. Additionally, direct heat could result in sleep disturbance, exhaustion, and heat stress associated with suicide $(56,123)$. Moreover, the correlation between mental illness and increase of temperature depends on latitude and factors that go beyond geography, such as cultural, political, and socio-behavioral factors (120). In the tropics, temperature fluctuations show a clear connection to negative agricultural, economic, and political situations. This is clearly seen in poor countries, which are more vulnerable to weather and climate fluctuation than wealthier countries (95). As described above, a single disaster, like a hurricane or flooding, has profound effects on mental health, in direct and acute manners. Furthermore, heat waves and extremely high temperatures expose the population to the possible onset of mental disorders. Sensitivity of mental disorders to temperature should not be underestimated when compared to other heatrelated physical diseases that are commonly studied. Naturally, the levels of exposure to high temperatures can vary, affecting populations in different geographical areas, thus leading to greater challenges in the study of risks (120). Studies show higher risks of mental-disorder correlated to warmer temperatures, specifically mania in the elderly, as well as a positive association with transient mental disorders and episodic mood disorders and an increase in hospital admissions for mental illness within a few days after warmer temperatures. When temperature rose over a threshold of about $20^{\circ} \mathrm{C}$, there is an increase in drug-related mental disorders. Furthermore, there is also a correlation with increased mortality and morbidity risks among people with mental and behavioral disorders (120). Increases in hospital emergency room visits are also shown for many of mental illnesses such as mood disorders (124), substance abuse, behavior disorders, neurotic disorders, and schizophrenia and schizotypal disorders. People are more affected by high temperature especially if they have schizophrenia, schizotypal disorders, and mood disorders (121). During the increase of temperature, there is a risk of mental states of aggression resulting in violence and self-harm, inflicted injury/homicide, and self-injury/suicide (122). Many studies found no significant associations with cold temperatures $(51,120)$.

\section{Increase in Sea Level}

Global sea level is projected to rise between 30 to 121 centimeters by 2100 , due to the influx of water from melting glaciers and the expansion of seawater as it warms (125). There are many factors that contribute to the increase of water (melting glaciers specifically in Greenland and Antarctic as well as worldwide), as well as changes in rainfall patterns and increasing frequency of severe weather such as flooding (126-129). Countries with lowlying areas, small islands like those in the Indian or Pacific Oceans, are concerned that their land areas might decrease due to flooding and coastal erosion. Consequently, many people could be forced to migrate to other countries leading a persistent worry and thoughts of relocation (128). Specific fears of encirclement or siege by the sea would replace the population's normal relationship with the sea or ocean (130).

\section{Deforestation}

Deforestation occurs due to the loss of plant biomass caused by climatic events and the direct action of mankind, driven by agriculture, animal grazing, and mining (131). There has been an enormous loss of forests due to human activity. News regarding such events have a stressogenic impact on western populations, due to the increased ecological awareness. People believe that an important world heritage has been damaged and lost. This feeling is now known as a biospheric concern. On the other hand, for indigenous populations, deforestation has a deeper impact, leading to profound maladaptive disorders and depression. In general, people believe that forests are a source of health and protection from various types of stress (132).

Urban green areas help maintain low temperatures in the city during the summer months, improve air quality, and reduce people's stress level (133). An ever-increasing number of studies shown that living in green urban spaces leads to health benefits, including better physical and mental health and a longer life expectancy (134). Studies suggest that the positive influence of nature on health can be observe especially between vulnerable groups such as the elderly, those in rehabilitation for mental disorders, and individuals in crisis rehabilitation (135). In the older population, contact with parks and green areas has been linked with slower cognitive decline. Moreover, children benefit from living in greener urban areas, such as better spatial working memory, improved attentional control and capacity, and higher 
academic achievement, particularly in mathematics (136), as well as improved behavior and emotional development, and positive structural changes in the brain (134). Moreover, green areas and parks in childhood have a preventive effect on the risk of developing various mental disorders later in life. More greenery in urban areas creates higher social cohesion and increases people's physical activity level, therefore improving children's cognitive development (137). In general, subjects living more urban green areas have a better quality of life. Unfortunately, those people who could get more benefits from a change of exposure often do not have sufficient resources or capacity to move to more healthy environments (138).

Landscape modification: landscape modification can induce individuals to develop a profound sense of loss of connection and detachment from the environment they know. Solastalgia is a term that describes this type of loss, especially when a person finds it difficult to adapt to environmental changes, possibly creating risks for mental health (53). Solastalgia describes a complex phenomenon that can have an impact on psychological levels, similar to that experienced by people who are forced to migrate (139). Biospheric concern refers to a type of stress that people feel when they see vulnerable nature such as plants or animals and the environment (140). Daily life can undergo variation due to climate change and when people lose their autonomy and control, they could experience a deep psychological change. For example, the loss of employment related to environmental changes can lead to a loss of individual identity. Immediately after a disaster, damages on social or community sources, or lack on food and medical services, could results in many acute consequences for the psychological well-being (139). In contrast, slow change of the environment due to climate change, like changes in usual weather or rising sea levels, will cause acute and chronic psychopathologic trauma and shock, PTSD, depression, anxiety, suicide, substance or alcohol abuse, aggressiveness and violence, difficulties in social and interpersonal relationships, loss of personally important places, alteration of social ties, loss of autonomy, and control, as well as personal and professional identity, leading to the emergence of feelings of helplessness and fear, solastalgia, and eco-anxiety (45).

\section{Economic Impact}

After ecological and environmental changes in a country, economic crises can occur and lead to an increase in suicide rates and other mental and behavioral disturbances especially working men (141). This type of stress, when associated with low socioeconomic status, paired with limited access to resources and reduced health, can lead to a diminished ability to cope. Economic difficulties that last over time or in conjunction with other factors, lead to a physical, cognitive, psychological, and social malfunction with a decrease in well-being and health (142). Both economic and climatic variables are strongly correlated with suicide, with $62.4 \%$ of male and $41.7 \%$ of female suicide rate variability across the continent (141).

\section{Exposure Groups}

Certain people are indeed more vulnerable to the potential impacts of climate change on mental health. There are communities that are more vulnerable to such events. This impact implies psychological effects (45) especially in vulnerable groups like children, the elderly, the chronically ill, people with mobility impairments, pregnant and postpartum women, people with mental illness, and those with lower socioeconomic status. Consequently, climate change has worsened global economic inequality (143). The more temperature shifts from optimum levels, the more there will be groups that cannot cope. A striking example is the traditional native populations. Different studies have considered the effect of climate change on native communities (such as first nations and aborigines), highlighting aspects of vulnerability and resilience (144, 145). Among these populations, the elderly is a clear example of difficulty in re-adaptation. These minorities and atrisk groups, such as the Inuit communities, first nations, and aborigines (146), are experiencing rapid change in climatic conditions $(132,147,148)$. In the Canadian arctic, the Inuit refer to having a protective factor for their mental health and well-being in "being on the land". Melting ice and change in weather conditions are strongly linked to the impairment of these protective factors due to a decrease in access to land with some of the highest rates of youth suicide that have been documented among Inuit youth (149).

Climate change is a social determinant for mental health (150). Strong impact has been noted on refugees and migrants (151), ethnic minorities, the homeless or vulnerable populations such as the poor in countries like India, China, and Brazil (152). Women, those with low socioeconomic status, living in poverty, with scarce economic and social resources, reduction of social support, and mental health problems existing before the events, along with traumatic experiences (death or life risk, serious injury or sexual assault) and stressors, represent vulnerable groups that tend to develop new mental disorders or see their previous problems worsen (49). After climate disasters, children typically show more severe disturbances than adults, with more severity and prevalence with regard to the onset of PTSD and depression. (71).

Residential populations in changing territories are subjected to new environmental conditions. For these people, this violation of the usual context is experienced with passivity and a sense of powerlessness. Many studies show that when people experience feelings of loss, helplessness, and frustration caused by their inability to cope with climate change, a term today coined as ecoanxiety (45, 153). People may also experience feelings of uncertainty and anticipation of the unknown regarding climate change. This leads to a psychological distance, a perception of distance, when a climatic event occurs as near or far, at a temporal, spatial, and s ocial level (51). In response to growing ecoanxiety and various type of biospheric concern, psychotherapists are pioneering a new field of treatment, termed "ecopsychology". It is important for doctors to teach patients to accept their own powerlessness. For example, when 
it starts raining, some patients have episodes of anxiety because they think of the past flooding with fear of losing the house again due to the flood. "Ecological grief" is a recorded grief and anxiety spread among the native Inuit to describe what they have seen (154).

These new words are emerging from recent observations on the impact and power that climate change has on mental health. It will certainly take time and further studies in order to identify these new diseases and disorders. The DSM-5 and ICD-10 offer no specific references to mental disorders related to climate change. The chapter "Other conditions that may be a focus of clinical attention" in the DSM-5 contains the section "Economic Problems" where the following conditions are listed: lack of adequate food or safe drinking water, extreme poverty, low income, insufficient social insurance, or welfare support. In the section "Problems Related to other Psychosocial, Personal and Environmental Circumstances" the following conditions are listed: exposure to disaster, war, or other hostilities (155).

Certain groups and communities are now beginning to experience disruptions with regard to social, economic, and environmental determinants. When exposed to climate change, a population experiences constant uncertainty, anxiety, loss, disruption, displacement, and fear even before a disaster has even occurred. Climate change negatively impact on mental health and wellbeing with unequal distribution within and among communities (156). After a natural disaster has occurred, damage and efforts to repair it have increased the disparity of wealth between races (this has been shown in United States). There has been a clear-cut increase with regard to inequality in countries that are frequently hit by extreme events. When certain areas receive more redevelopment aid, racial inequality is going to be amplified (157). When farmers in various parts of the world perceive the psychological pressure of climate change, they are motivated to engage in different strategies in order to adapt to climate change (51).

\section{DISCUSSION}

\section{Summary of Main Findings}

There is a strong link between natural disasters and mental disorders. In the future, climate change will bring about an increasing frequency of extreme weather. We know that weather changes may induce psychopathological phenomena such as seasonal affective disorders to weather sensitivity and meteoropathic conditions. Specific symptom patterns, below the pathological threshold, may be devised in reaction to various atmospheric changes and perturbations: temperature, humidity, rain, barometric pressure, brightness, rate of air flow, air ionization, thunderstorms, and sudden shifts of some of these factors (158). What is also seen as a temperamental trait has been called "meteorosensitivity". Living organisms may be biologically more prone to suffer the effect of atmospheric events on mind and body. On the other hand, meteoropathic subjects are those individuals who develop a specific illness or the worsening of an existing disease as a consequence of climatic changes. Psychophysical symptoms include: mood disturbances, irritability, anxiety, mental and physical weakness, hypertension, headache, hyperalgesia and pains, and autonomic symptoms (159). Moreover, air pollution can induce neural instability (158). Scarce rain and low average temperature have been found to lead to psychiatric visits in emergency departments (160). Hippocrates himself wrote: "Whoever wishes to investigate medicine properly, should proceed a so: in the first place to consider the seasons of the year ... then the winds, the hot and the old ... we must also consider the qualities of the water ..." (161). Weather can impact everyday activity and changes in the behavior result from physical characteristics of the environment. With global climate change, these psychopathological phenomena due to sensitivity to normal weather conditions can today be studied within a wider dimension.

Climate change can lead to extreme weather, which include large storms, flooding, droughts, and heat waves, and it has effects not only on physical health (e.g. degraded air quality) through the spread of diseases and the reemergence of existing diseases, but also on mental health. Mental health consequences of natural disasters cover a wide range of disorders.

The connection between climate change and its consequences on mental health is far from reaching a clear conclusion. The complexity of current studies highlights this challenge. This difficulty is largely due to the heterogeneity in what to measure and how to measure the impact of climate change. Attempts to discover the underlying mechanisms of adaptation, as well as the definition of deviations from normality in extreme climate events, and finally attempts to define direct cause-effect relationships are all challenging tasks. Socio-behavioral factors, culture, information, and preparedness all play a relevant role in peri-traumatic experience, determining collective resilience or psychological disruption and exhaustion. Studies that empirically established connections between climate change and mental health consequences are now coming forth in literature. Impact of climate change on mental health can occur either directly with immediate effect (heat waves), or indirectly in the short term during extreme events (floods, tornadoes, hurricanes), or indirectly in the long term (changes in the territory such as prolonged droughts, increase in the sea levels, deforestation, forced migration). All these events affect the mental health of a population, with the appearance of psychiatric conditions such as PTSD, mood disorders such as depression, anxiety, increased suicide rate and substance use, as well as increased aggressive behavior. Climate change will also exert the greatest impact on groups of vulnerable populations that therefore have an increased probability of developing psychopathologies: women, the elderly, children, people with previous psychiatric illnesses who can consequently worsen their mental condition, and people with low income or poor social network, as well as indigenous and native communities. Extreme weather events seem to have the power to also destroy social ties (162). Vulnerable communities are those located in exposed regions (e.g. coastal regions, where windstorm or extreme heat can occur).

Climate change will produce profound changes in the environment and alter lifestyles, while also generating 
environmentally-motivated migration (random asylum seekers and climatic refugees). These groups of people, forced to migrate, already have their own psychological vulnerabilities (162). They may find it difficult even to identify the appropriate emotional control for specific climate changes. Moreover, extreme events produce different types of psychopathological reactions over time, as there are acute, sub-acute, and long-term impacts on mental health. Mental adaptation and certain behavioral patterns will develop following the chronology of events: in the pre-alert phase, during the disaster and after the event (163). Long-term consequences are difficult to define. Consequences of climate change, such as economic and social difficulty, contribute not only to the increase in the incidence of mental illnesses in the affected population, but also in the subsequent generations. Literature analyzes single types of climatic events, since certain consequent disorders are specific while others generally occur in different extreme events (162). Being able to understand what this change entails makes it possible to program early interventions and actions for a population's mental health.

\section{Limitations}

Studies on the consequences that climate change has on mental health are still at their very beginning. In the future, it would be useful to further investigate the correlation between psychiatric diseases and extreme events. We did not find any study on how people react to the changes in landscape such as deglaciation, disappearance of rivers, desertification, fires, and water shortages. A greater understanding of the characteristics of acute, sub-acute, and long-term consequences is an also desirable goal. Furthermore, we believe that future research in climate change and mental health will include multi-disciplinary studies. Scholars should focus on how different vulnerable groups can be affected by natural disasters and climate change, as well as how to make use of the available protective measure and healthcare resources. A limitation of the present descriptive review is the lack of a meta-analysis as a methodological completion of the systematic review. This could be useful in the upcoming research in order to establish specific causal associations between climate change and mental health consequences (symptoms and disorders).

\section{Conclusions}

Based on the studies and literature reviewed in this paper, there appears to be strong evidence of the influence that the climate change exerts on mental health.

This study examined the effects of global climate change on the general population, as well as at-risk groups and vulnerable communities. We chose to focus on extreme events, such as those produced by temperature increase, heat waves, floods, drought, tornadoes, hurricanes, and wildfire. Consequences have been described in terms of distress symptoms, suicide rates, and clinical disorders (depression, anxiety, sleep disturbances, PTSD, etc.). Even though some of these events may occur in a slower and less acute manner (e.g. temperature increase or droughts), most of these events are rapid in their onset and manifest themselves in the form of disasters, the reactions to which often see PTSD as a prototypical model. On the other hand, we could support that people who are more sensitive to weather and atmospheric phenomena may be more affected by gradually occurring global climate changes and their consequences, such as global warming, rising sea levels, landscape changes, and loss of familiar environmental landmarks.

Moreover, the disappearance of animal and plant species may bring about feelings of hopelessness and depression. When a person's feelings about their environment are considered, it should be clear that we are moving toward a cultural and contextual dimension. The wound inflicted to this symbolic domain causes more complex psychopathological consequences, such as identity disorders (164) or long-term personality changes (119), as seen in trauma related to extreme weather events and loss of familiar landscape, or dissociative syndromes (165) as seen in trauma related to extreme events or in migratory syndromes. Lastly, we also need to learn how meteoropathy and weather sensitivity, paired with environmental and climate changes, deeply influence the psychosomatic sphere of mankind, activating mechanisms of somatization and conversion, and inducing somatic disorders and physical illnesses or worsening previously existing distress at the body level. These psychiatric disorders, in quality and quantity, are linked to the type of evolution of post-modern societies. In short, all of these issues need to be more extensively studied and clinical experience should be gained in order to support our provisional conclusions. The challenge of climate change will be protracted in the upcoming years. Therefore, this branch of "ecopsychiatry" will surely be supported by new data sets and further studies.

\section{AUTHOR CONTRIBUTIONS}

PC, SB, and LJ all contributed to the brainstorming, writing, and critical review of this manuscript. LJ edited the manuscript.

\section{FUNDING}

Funding for this study was provided by Fondazione Policlinico Gemelli - Institute of Psychiatry, Catholic University, Rome, Italy. The funders had no role in this study design, data collection and analysis, decision to publish, or preparation of the manuscript.

\section{ACKNOWLEDGMENTS}

We would like to thank the World Psychiatric Association, Section on Ecology Psychiatry \& Mental Health for the scientific support. 


\section{REFERENCES}

1. Cianconi P, Tarricone I, Ventriglio A, De Rosa C, Fiorillo A, Saito T, et al. Psychopathology in postmodern societies. J Psychopathol (2015) 21:431-9.

2. Diffenbaugh NS, Scherer M. Observational and model evidence of global emergence of permanent, unprecedented heat in the 20(th) and 21(st) centuries. Clim Change (2011) 107:615-24. doi: 10.1007/s10584-011-0112-y

3. Church JA, Clark PU, Cazenave A, Gregory JM, Jevrejeva S, Levermann A, et al. 2013: Sea Level Change. In: Climate Change 2013: The Physical Science Basis. Contribution of Working Group I to the Fifth Assessment Report of the Intergovernmental Panel on Climate Change. Cambridge, United Kingdom and New York, NY, USA: Cambridge University Press (2013).

4. NASA Global climate change. Severe thunderstorms and climate change. . [Online] April 7, 2013. [Cited: May 26, 2019.] https://climate.nasa.gov/news/ 897/severe-thunderstorms-and-climate-change/.

5. Seneviratne SI, Nicholls N, Easterling D, Goodess CM, Kanae S, Kossin J, et al. Changes in climate extremes and their impacts on the natural physical environment. Cambridge, UK, and New York, NY, USA: Cambridge University Press (2012). A Special Report of Working Groups I and II of the IPCC.

6. Trenberth KE. Framing the way to relate climate extremes to climate change. Clim Change (2012) 115:283-90. doi: 10.1007/s10584-012-0441-5

7. Jentsch A, Kreyling J, Beierkuhnlein C. A new generation of climate change experiments: events, not trends. Front In Ecol Environ (2007) 5:365-74. doi: 10.1890/1540-9295(2007)5[365:ANGOCE]2.0.CO;2

8. Jentsch A, Beierkuhnlein C. Research frontiers in climate change: Effects of extreme meteorological events on ecosystems. C R Geosci (2008) 340:624-8. doi: 10.1016/j.crte.2008.07.002

9. IPCC. Managing the Risks of Extreme Events and Disasters to Advance Climate Change Adaptation. Cambridge, UK, and New York, NY, USA: Cambridge University Press (2012). A Special Report of Working Groups I and II of the Intergovernmental Panel on Climate Change.

10. WHO. Mental health action plan 2013-2020. Geneva: WHO Document Production Services (2013).

11. Steffen W, Grinevald J, Crutzen P, Mcneill J. The Anthropocene: conceptual and historical perspectives. $R$ Soc (2011) 369:842-67. doi: 10.1098/ rsta.2010.0327

12. Trenberth KE, Fasullo JT, Shepherd TG. Attribution of climate extreme events. Nat Clim Change (2015) 5:725-30. doi: 10.1038/nclimate2657

13. Christidis N, Jones GS, Stott PA. Dramatically increasing chance of extremely hot summers since the 2003 European heatwave. Nat Clim Change (2014) 5:46-50. doi: 10.1038/nclimate2468

14. Mann ME, Rahmstorf S, Kornhuber K, Steinman BA, Miller SK, Coumou D. Influence of Anthropogenic Climate Change on Planetary Wave Resonance and Extreme Weather Events. Sci Rep (2017) 7:45242. doi: 10.1038/ srep 45242

15. Petoukhov V, Rahmstorf S, Petri S, Schellnhuber HJ. Quasiresonant amplification of planetary waves and recent Northern Hemisphere weather extremes. Proc Natl Acad Sci (2013) 110:5336-41. doi: 10.1073/pnas.1222000110

16. Berry HL, Waite TD, Dear KB, Capon AG, Murray V. The case for systems thinking about climate change and mental health. Nat Clim Change (2018) 8:282-90. doi: 10.1038/s41558-018-0102-4

17. Mimura N, Pulwarty RS, Duc DM, Elshinnawy I, Redsteer MH, Huang HQ, et al. Adaptation planning and implementation. In: Climate Change 2014: Impacts, Adaptation, and Vulnerability. Part A: Global and Sectoral Aspects. Cambridge, UK, and New York, NY, USA: Cambridge University Press (2014) Contribution of Working Group II to the Fifth Assessment Report of the IPCC.

18. Rosenzweig C, Karoly D, Vicarelli M, Neofotis P, Wu Q, Casassa G, et al. Attributing physical and biological impacts to anthropogenic climate change. Nature (2008) 453:353-7. doi: 10.1038/nature06937

19. Rahmstorf S, Coumou D. Increase of extreme events in a warming world. Proc Natl Acad Sci (2011) 108:17905-9. doi: 10.1073/pnas.1101766108

20. Meehl GA, Tebaldi C. More Intense, More Frequent, and Longer Lasting Heat Waves in the 21st Century. Science (2004) 305:994-7. doi: 10.1126/ science.1098704

21. Dai A. Drought under global warming: a review. WIRES Clim Change (2011) 2:45-65. doi: $10.1002 /$ wcc. 81
22. Fischer EM, Seneviratne SI. Soil Moisture-Atmosphere Interactions during the 2003 European Summer Heat Wave. J Climate (2007) 20:5081-99. doi: 10.1175/JCLI4288.1

23. Petrie RE, Shaffrey LC, Sutton RT. Atmospheric response in summer linked to recent Arctic sea ice loss. Q J R Meteorol Soc (2015) 141:2070-6. doi: 10.1002/qj.2502

24. Diffenbaugh NS, Singh D, Mankin JS, Horton DE, Swain DL, Touma D, et al. Quantifying the influence of global warming on unprecedented extreme climate events. PNAS (2017) 114:4881-6. doi: 10.1073/pnas.1618082114

25. Coumou D, Rahmstorf S. A decade of weather extremes. Nat Climate Change (2012) 2:491-6. doi: 10.1038/nclimate1452

26. Scheffer M. Critical transitions in nature and society. New Jersey: Princepton University Press (2009).

27. Rahmstorf S. Anthropogenic climate change: the risk of unpleasant surprises. In: Brockmann KL, Stronzik M, editors. Flexible mechanisms for an efficient climate policy (2000). p. 7-11.

28. IPCC. Climate Change 2007: The Physical Science Basis. Cambridge, United Kingdom and New York, NY, USA: Cambridge University Press (2007) Contribution of Working Group I to the Fourth Assessment Report of the Intergovernmental Panel on Climate Change.

29. Peterson TC, Heim Jr. RR, Hirsch R, Kaiser DP, Brooks H, Diffenbaugh NS, et al. Monitoring and understanding changes in heat waves, cold waves, floods and droughts in the United States: State of knowledge. Bull Am Meteorol Soc (2013) 94:821-34. doi: 10.1175/BAMS-D-12-00066.1

30. Nogués-Bravo D, Rodríguez-Sánchez F, Orsini L, de Boer E, Jansson R, Morlon $\mathrm{H}$, et al. Cracking the Code of Biodiversity Responses to Past Climate Change. Trend In Ecol Evol (2018) 33:765-76. doi: 10.1016/ j.tree.2018.07.005

31. Strona G, Bradshaw CJA. Co-extinctions annihilate planetary life during extreme environmental change. Sci Rep (2018) 8:1-12. doi: 10.1038/s41598018-35068-1

32. Romero GQ, Gonçalves-Souza T, Kratina P, Marino NAC, Petry WK, Sobral-Souza T, et al. Global predation pressure redistribution under future climate change. Nat Climate Change (2018) 8:1087-91. doi: $10.1038 / \mathrm{s} 41558$

33. Humphrey V, Zscheischler J, Ciais P, Gudmundsson L, Sitch S, Seneviratne SI. Sensitivity of atmospheric CO2 growth rate to observed changes in terrestrial water storage. Nature (2018) 560:628-31. doi: 10.1038/s41586018-0424-4

34. OBrien LV, Berry HL, Coleman C, Hanigan IC. Drought as a mental health exposure. Environ Res (2014) 131:181-7. doi: 10.1016/j.envres.2014.03.014

35. Abel GJ, Brottrager M, Cuaresma JC, Muttarak R. Climate, conflict and forced migration. Global Environ Change (2019) 54:239-49. doi: 10.1016/ j.gloenvcha.2018.12.003

36. IPCC. Global warming of $1.5^{\circ} \mathrm{C}$. Switzerland: Technical Support Unit (2018).

37. Deutsch CA, Tewksbury JJ, Tigchelaar M, Battisti DS, Merrill SC, Huey RB, et al. Increase in crop losses to insect pests in a warming climate. Science (2018) 361:916-9. doi: 10.1126/science.aat3466

38. Climate Council. Climate Change, Security and Australia"s Defence Force. Australia: Climate Council of Australia Limited (2015).

39. Loganovsky KN, Loganovskaja T, Marazziti D. Ecological psychiatry/ neuropsychiatry: is it the right time for its revival? Clin Neuropsychiatry (2019) 16:124.

40. Bartolome C, Princevac M, Weise DR, Mahalingam S, Ghasemian M, Venkatram A, et al. Laboratory and numerical modeling of the formation of superfog from wildland fires. Fire Saf J (2019) 106:94-104. doi: 10.1016/ j.firesaf.2019.04.009

41. Wight J, Middleton J. Climate change: the greatest public health threat of the century. BMJ (2019) 365:I2371. doi: 10.1136/bmj.12371

42. Silverman GS. Systematic Lack of Educational Preparation in Addressing Climate Change as a Major Public Health Challenge. Am J Public Health (2019) 109:242-243. doi: 10.2105/ajph.2018.304818

43. Bourque F, Willox AC. Climate change: The next challenge for public mental health? Int Rev Psychiatry (2014) 26:415-22. doi: 10.3109/09540261.2014.925851

44. Berry HL, Bowen K, Kjellstrom T. Climate change and mental health: A causal pathways framework. Int J Public Health (2010) 55:123-32. doi: 10.1007/s00038-009-0112-0 
45. APA. Mental Health and Our Changing Climate: Impacts, Implications, and Guidance. Washington, DC (2017).

46. Blanc J, Spruill T, Butler M, Casimir G, Girardin JL. 0885 Is Resilience A Protective Factor For Sleep Disturbances Among Earthquake Survivors? Sleep (2019) 42(Supplement_1):A356. doi: 10.1093/sleep/zsz067.883

47. Ursano RJ, Morganstein JC, Cooper R. Resource Document on Mental Health and Climate Change. APA Document (2017) 1

48. U.S Global Change, Research Program. The Impacts of Climate Change on Human Health in the United States: A Scientific Assessment. Washington: U.S Global Change Research Program (2016).

49. Gruebner O, Lowe SR, Sykora M, Shankardass K, Subramanian SV, Galea S. A novel surveillance approach for disaster mental health. PloS One (2017) 12:1-15. doi: 10.1371/journal.pone.0181233

50. Hsiang SM, Burke M, Miguel E. Quantifying the influence of climate on human conflict. Science (2013) 341:1212-26. doi: 10.1126/science.1235367

51. Acharibasam JW, Anuga SW. Psychological distance of climate change and mental health risks assessment of smallholder farmers in Northern Ghana: Is habituation a threat to climate change? Climate Risk Manage (2018) 21:1625. doi: 10.1016/j.crm.2018.04.002

52. Gronlund CJ, Cameron L, Shea C, O'Neill MS. Assessing the magnitude and uncertainties of the burden of selected diseases attributable to extreme heat and extreme precipitation under a climate change scenario in Michigan for the period 2041-2070. Environ Health (2019) 18:1-17. doi: 10.1186/s12940-019-0483-5

53. Padhy SK, Sarkar S, Panigrahi M, Paul S. Mental health effects of climate change. Indian J Occup Environ Med (2015) 19:3-7. doi: 10.4103/0019-5278.156997

54. WHO. Gender, Climate change and Health. Switzerland: World Health Organization (2014), ISBN: 9789241508186.

55. Anderson C. Heat and Violence. Am psychol Soc (2001) 10:33-8. doi: 10.1111/1467-8721.00109

56. Burke M, González F, Baylis P, Heft-Neal S, Baysan C, Basu S, et al. Higher temperatures increase suicide rates in the United States and Mexico. Nat Climate Change (2018) 8:723-9. doi: 10.1038/s41558-018-0222-x

57. Towers S, Chen S, Malik A, Ebert D. Factors influencing temporal patterns in crime in a large American city: A predictive analytics perspective. PloS One (2018) 13:1-27. doi: 10.1371/journal.pone.0205151

58. Murakami H, Wang Y, Yoshimura H, Mizuta R, Sugi M, Shindo E, et al. Future Changes in Tropical Cyclone Activity Projected by the New HighResolution MRI-AGCM. Am Meteorol Soc (2012) 39:3237-60. doi: 10.1175/ JCLI-D-11-00415.1

59. Evan AT, Kossin JP, Chung CE, Ramanathan V. Arabian Sea tropical cyclones intensified by emissions of black carbon and other aerosols. Nature (2011) 479:94-7. doi: 10.1038/nature 10552

60. Fahy B, Brenneman E, Chang H, Shandas V. Spatial analysis of urban flooding and extreme heat hazard potential in Portland, OR. Int J Disaster Risk Reduction (2019) 39:101117. doi: 10.1016/j.ijdrr.2019.101117

61. Nahar N, Blomstedt Y, Wu B, Kandarina I, Trisnantoro L, Kinsman J. Increasing the provision of mental health care for vulnerable, disaster-affected people in Bangladesh. BMC Public Health (2014) 14:1-9. http://www.biomedcentral.com/ 1471-2458/14/708. doi: 10.1186/1471-2458-14-708

62. Syvitski JPM, Kettner AJ, Overeem I, Hutton EWH, Hannon MT, Brakenridge GR, et al. Sinking deltas due to human activities. Nat Geosci (2009) 2:681-6. doi: 10.1038/ngeo629

63. Higgins S, Overeem I, Tanaka A, Syvitski JPM. Land subsidence at aquaculture facilities in the Yellow River delta, China. Geophys Res Lett (2013) 40:3898-902. doi: 10.1002/grl.50758

64. Chowell G, Mizumoto K, Banda JM, Poccia S, Perrings C. Assessing the potential impact of vector-borne disease transmission following heavy rainfall events: a mathematical framework. Philos Trans $R$ Soc B: Biol Sci (2019) 374:1-9. doi: 10.1098/rstb.2018.0272

65. Bei B, Bryant C, Gilson KM, Koh J, Gibson P, Komiti A, et al. A prospective study of the impact of floods on the mental and physical health of older adults. Aging Ment Health (2013) 17:992-1002. doi: 10.1080/13607863.2013.799119

66. Shultz JM, McLean A, Herberman Mash HB, Rosen A, Kelly F, Solo-Gabriele HM, et al. Mitigating flood exposure: Reducing disaster risk and trauma signature. Disaster Health (2013) 1:30-44. doi: 10.4161/dish.23076

67. Michelozzi P, de' Donato F. Climate changes, floods, and health consequences. Il Pensiero Scientifico Editore (2014) 105:48-50. doi: 10.1701/1417.15695
68. Carlos Otero J, Njenga FG. Lessons in posttraumatic stress disorder from the past: Venezuela floods and Nairobi bombing. J Clin Psychiatry (2006) 67:56-63.

69. Bandla S, Nappinnai NR, Gopalasamy S. Psychiatric morbidity in December 2015 flood-affected population in Tamil Nadu, India. Int J Soc Psychiatry (2019) 65:338-44. doi: 10.1177/0020764019846166

70. Senthilingam M. Depression, anxiety, PTSD: The mental impact of climate change, CNN edition. , [Online] March 14, 2017. [Cited: May 26, 2019.] http://edition.cnn.com/2017/03/14/health/climate-change-mental-healtheprise/index.html.

71. Peng M, Liu A, Zhou J, Wen S, Li S, Yang T, et al. Association between posttraumatic stress disorder and preflood behavioral characteristics among children aged 7-15 years in Hunan, China. Med Princ Pract (2011) 20:33640. doi: $10.1159 / 000323757$

72. Pullen LC. Disaster Preparedness Should Focus on Children's Needs. MedScape Psychiatry. https://www.medscape.com/viewarticle/852842.

73. Stanke C, Murray V, Amlôt R, Nurse J, Williams R. The effects of flooding on mental health: Outcomes and recommendations from a review of the literature. PloS Curr (2012) 4:1-25. doi: 10.1371/4f9f1fa9c3cae

74. Lieberman-Cribbin W, Liu B, Schneider S, Schwartz R, Taioli E. SelfReported and FEMA Flood Exposure Assessment after Hurricane Sandy: Association with Mental Health Outcomes. PloS One (2017) 12:1-15. doi: 10.1371/journal.pone. 0170965

75. Fernandez A, Black J, Jones M, Wilson L, Salvador-Carulla L, Astell-Burt T, et al. Flooding and Mental Health: A Systematic Mapping Review. PloS One (2015) 10:1-20. doi: 10.1371/journal.pone.0119929

76. Hetherington E, McDonald S, Wu M, Tough S. Risk and Protective Factors for Mental Health and Community Cohesion After the 2013 Calgary Flood. Disaster Med Public Health Prep (2017) 12:470-7. doi: 10.1017/dmp.2017.91

77. Veenema TG, Thornton CP, Lavin RP, Bender AK, Seal S, Corley A. Climate Change-Related Water Disasters' Impact on Population Health. J Nurs Scholarship (2017) 49:625-34. doi: 10.1111/jnu.12328

78. Reifels L, Bassilios B, Spittal MJ, King K, Fletcher J, Pirkis J. Patterns and Predictors of Primary Mental Health Service Use Following Bushfire and Flood Disasters. Disaster Med Public Health Prep (2015) 9:275-82. doi: 10.1017/dmp.2015.23

79. Kessler RC, Galea S, Jones RT, Parker HAHurricane Katrina Community Advisory Group. Mental Illness and Suicidality after Hurricane Katrina. Bull World Health Organ (2006) 84:930-9. doi: 10.2471/BLT.06.033019

80. Galea S, Brewin CR, Gruber M, Jones RT, King DW, King LA, et al. Exposure to Hurricane-Related Stressors and Mental Illness After Hurricane Katrina. Arch Gen Psychiatry (2007) 64:1427-34. doi: 10.1001/archpsyc.64.12.1427

81. Neria Y, Shultz JM. Mental Health Effects of Hurricane Sandy: Characteristics, Potential Aftermath, and Response. JAMA (2012). 308: 2571-2. doi: 10.1001/jama.2012.110700

82. NASA global climate change. The Effects of Climate Change. In: Hurricanes Will Become Stronger and More Intense. [Online] [Cited: May 26, 2019.] https://climate.nasa.gov/effects/.

83. Keellings D, Ayala JJH. Extreme Rainfall Associated With Hurricane Maria Over Puerto Rico and Its Connections to Climate Variability and Change. Geophys Res Lett (2019) 46:2964-73. doi: 10.1029/2019GL082077

84. Bourque LB, Siegel JM, Kano M, Wood MM. Weathering the Storm: The Impact of Hurricanes on Physical and Mental Health. Ann Am Acad (2006) 604:129-51. doi: 10.1177/0002716205284920

85. Becquart N, Naumova E, Singh G, Chui K. Cardiovascular Disease Hospitalizations in Louisiana Parishes' Elderly before, during and after Hurricane Katrina. Int $J$ Environ Res Public Health (2018) 16:1-28. doi: 10.3390/ijerph16010074

86. Nomura Y, Davey K, Pehme PM, Finik J, Glover V, Zhang W, et al. Influence of in utero exposure to maternal depression and natural disaster-related stress on infant temperament at 6 months: The children of Superstorm Sandy. Infant Ment Health J (2019) 40:204-16. doi: 10.1002/imhj.21766

87. Ruskin J, Rasul R, Schneider S, Bevilacqua K, Taioli E, Schwartz RM. Lack of access to medical care during Hurricane Sandy and mental health symptoms. Prev Med Rep (2018) 10:363-9. doi: 10.1016/j.pmedr.2018.04.014

88. Schultz JM, Galea S. Mitigation the mental and physical health consequences of hurricane Harvey. JAMA (2017) 318:1437-8. doi: 10.1001/jama.2017.14618

89. Lin S, Lu Y, Justino J, Dong G, Lauper U. What Happened to Our Environment and Mental Health as a Result of Hurricane Sandy? Disaster Med Public Health Prep (2016) 10:314-9. doi: 10.1017/dmp.2016.51 
90. Aponte J. Hurricanes and Mental Health. Hisp Health Care Int (2018) 16:110-1. doi: $10.1177 / 1540415318804290$

91. Taioli E, Tuminello S, Lieberman-Cribbin W, Bevilacqua K, Schneider S, Guzman M, et al. Mental health challenges and experiences in displaced populations following Hurricane Sandy and Hurricane Harvey: the need for more comprehensive interventions in temporary shelters. Epidemiol Community Health (2018) 72:867-70. doi: 10.1136/jech-2018-210626

92. Stocker TF, Qin D, Plattner GK, Tignor M, Allen SK, Boschung J, et al. IPCC, 2013: Climate Change 2013: The Physical Science Basis. Contribution of Working Group I to the Fifth Assessment Report of the Intergovernmental Panel on Climate Change. Cambridge, United Kingdom and New York, NY, USA: Cambridge University Press (2013).

93. Marvel K, Cook BI, Bonfils CJW, Durack PJ, Smerdon JE, Williams AP. Twentieth-century hydroclimate changes consistent with human influence. Nature (2019) 569:59-65. doi: 10.1038/s41586-019-1149-8

94. Demetillo MAG, Anderson JF, Geddes JA, Yang X, Najacht EY, Herrera SA, et al. Observing Severe Drought Influences on Ozone Air Pollution in California. Environ Sci Technol (2019) 53:4695-706. doi: 10.1021/acs.est.8b04852

95. Bathiany S, Dakos V, Scheffer M, Lenton TM. Climate models predict increasing temperature variability in poor countries. Sci $A d v$ (2018) 4:1-10. doi: 10.1126/sciadv.aar5809

96. Willox CA, Harper S, Ford J, Landman K, Houle K, Edge V. The Rigolet Inuit Community Government Climate change and mental health: a case study from Rigolet, Nun-atsiavut, Labrador, Canada. Clim Change (2013) 121:1-16. doi: 10.1007/s10584-013-0875-4

97. Le Houérou HN. Climate change, drought and desertification. J Arid Environ (1996) 34:133-85. doi: 10.1006/jare.1996.0099

98. Hanigan IC, Butler CD, Kokic PN, Hutchinson MF. Suicide and drought in New South Wales, Australia 1970-2007. PNAS (2012) 109:13950-5. doi: 10.1073/pnas.1112965109

99. Guiney R. Farming suicides during the Victorian drought: 2001-2007. Aust J Rural Health (2012) 20:11-5. doi: 10.1111/j.1440-1584.2011.01244.x

100. Deshpande RS. Suicide by Farmers in Karnataka: Agrarian Distress and Possible Alleviatory Steps. Econ Polit Wkly (2002) 37:2601-10. doi: 10.2307/ 4412301

101. Sarma EAS. Is Rural Economy Breaking Down? Farmers' Suicides in Andhra Pradesh. Econ Polit Wkly (2004) 39:3087-9. doi: 10.2307/4415247

102. Sena A, Freitas C, Feitosa Souza P, Carneiro F, Alpino T, Pedroso M, et al. Drought in the Semiarid Region of Brazil: Exposure, Vulnerabilities and Health Impacts from the Perspectives of Local Actors. PloS Curr (2018) 10:129. doi: 10.1371/currents.dis.c226851ebd64290e619a4d1ed79c8639

103. Carleton TA. Crop-damaging temperatures increase suicide rates in India. PNAS (2017) 114:8746-51. doi: 10.1073/pnas.1701354114

104. Clayton S, Manning CM, Hodge C. Beyond storms of droughts: The psychological impacts of climate change. Washington, DC: American Psychological Association and ecoAmerica (2014).

105. FAO. Migration, Agriculture and Climate Change - Reducing vulnerabilities and enhancing resilience. Rome (2017). I8297EN/1/12.17.

106. Human Rights Watch. "There is No Time Left" Climate Change, Environmental Threats, and Human Rights in Turkana County, Kenya. United States of America: Human Rights Watch (2015).

107. Mekonnen ZA, Riley WJ, Randerson JT, Grant RF, Rogers BM. Expansion of high-latitude deciduous forests driven by interactions between climate warming and fire. Nat Plants (2019) 5:952-8. doi: 10.1038/s41477-019-0495-8

108. Finlay SE, Moffat A, Gazzard R, Baker D, Murray V. Health Impacts of Wildfires. PloS Curr (2012) 4:e4f959951cce2c. doi: 10.1371/4f959951cce2c

109. McFarlane AC, Clayer JR, Bookless CL. Psychiatric morbidity following a natural disaster: an Australian bushfire. Soc Psychiatry Psychiatr Epidemiol (1997) 32:261-8. doi: 10.1007/BF00789038

110. Raphael B, Middleton W. Mental health responses in a decade of disasters: Australia, 1974-1983. Hosp Community Psychiatry (1987) 38:1331-7. doi: 10.1176/ps.38.12.1331

111. Laugharne J, van der Watt G, Janca A. After the fire: the mental health consequences of fire disasters. Curr Opin Psychiatry (2011) 24:72-7. doi: 10.1097/YCO.0b013e32833f5e4e

112. Adamis D, Papanikolaou V, Mellon RC, Prodromitis G. The impact of wildfires on mental health of residents in a rural area of Greece. A case control population based study. Eur Psychiatry (2011) 13:11-26. doi: 10.1016/S0924-9338(11)72893-0

113. Jones RT, Ribbe DP, Cunningham P, Weddle JD. Psychosocial Correlates of Wildfire Disaster: Post Disaster Adult Reactions. Fire Technol (2003) 39:103-17. doi: 10.1023/A:1024229812303

114. Famularo R, Fenton T, Augustyn M, Zuckerman B. Persistence of pediatric post traumatic stress after two years. Child Abuse Negl (1996) 20:1245-8. doi: 10.1016/S0145-2134(96)00119-6

115. Yelland C, Robinson P, Lock C, La Greca AM, Kokegei B, Ridgway V, et al. Bushfire impact on youth. J Traum Stress (2010) 23:274-7. doi: 10.1002/ jts. 20521

116. Nilamadhab K. Psychological impact of disasters on children: review of assessment and interventions. World J Pediatr (2009) 5:5-11. doi: 10.1007/ s12519-009-0001-x

117. Thomas N, Nigam S. Twentieth-Century Climate Change over Africa: Seasonal Hydroclimate Trends and Sahara Desert Expansion. J Climate (2018) 31:3349-70. doi: 10.1175/JCLI-D-17-0187.1

118. Ji F, Wu Z, Huang J, Chassignet EP. Evolution of land surface air temperature trend. Nat Clim Change (2014) 4:462-6. doi: 10.1038/ nclimate2223

119. Wei W, Lu JG, Galinsky AD, Wu H, Gosling SD, et al. Regional ambient temperature is associated with human personality. Nat Hum Behav (2017) 1:890-5. doi: 10.1038/s41562-017-0240-0

120. Chan EYY, Lam HCY, So SHW, Goggins WB, Ho JY, Liu S, et al. Association between Ambient Temperatures and Mental Disorder Hospitalizations in a Subtropical City: A Time-Series Study of Hong Kong Special Administrative Region. Int J Environ Res Public Health (2018) 14:1-19. doi: 10.3390/ ijerph15040754

121. Wang X, Lavigne E, Ouellette-kuntz H, Chen BE. Acute impacts of extreme temperature exposure on emergency room admissions related to mental and behavior disorders in Toronto, Canada. J Affect Disord (2014) 155:154-61. doi: 10.1016/j.jad.2013.10.042

122. Basu R, Gavin L, Pearson D, Ebisu K, Malig B. Examining the Association Between Apparent Temperature and Mental Health-Related Emergency Room Visits in California. Am J Epidemiol (2018) 187:4. doi: 10.1093/aje/ $\mathrm{kw} \times 295$

123. Noelke C, McGovern M, Corsi DJ, Jimenez MP, Stern A, Wing IS, et al. Increasing ambient temperature reduces emotional well-being. Environ Res (2016) 151:124-9. doi: 10.1016/j.envres.2016.06.045

124. Chen NT, Lin PH, Guo YL. Long-term exposure to high temperature associated with the incidence of major depressive disorder. Sci Total Environ (2019) 659:1016-20. doi: 10.1016/j.scitotenv.2018.12.434

125. NASA Global climate change. The Effects of Climate Change. In: Sea Level Will Rise 1-4 feet by 2100. [Online] California Institute of Technology. [Cited: May 26, 2019.] https://climate.nasa.gov/effects/.

126. Zemp M, Huss M, Thibert E, Eckert N, McNabb R, Huber J, et al. Global glacier mass changes and their contributions to sea-level rise from 1961 to 2016. Nature (2019) 568:382-6. doi: 10.1038/s41586-019-1071-0

127. Hino M, Belanger ST, Field CB, Davies AR, Mach KJ. High-tide flooding disrupts local economic activity. Sci Adv (2019) 5:1-9. doi: 10.1126/ sciadv.aau2736

128. Asugeni J, MacLaren D, Massey PD, Speare R. Mental health issues from rising sea level in a remote coastal region of the Solomon Islands: current and future. Australas Psychiatry (2015) 23:22-5. doi: 10.1177/1039856215609767

129. Minura N. Sea-level rise caused by climate change and its implications for society. Proc Jpn Acad (2013) 89:281-301. doi: 10.2183/pjab.89.281

130. Chan EYY, Ho JY, Hung HHY, Liu S, Lam HCY. Health impact of climate change in cities of middle-income countries: the case of China. Br Med Bull (2019) 130:5-24. doi: 10.1093/bmb/ldz011

131. Thom D, Golivets M, Edling L, Meigs GW, Gourevitch JD, Sonter LJ, et al. The climate sensitivity of carbon, timber, and species richness covaries with forest age in boreal-temperate North America. Global Change Biol (2019) 25:2446-58. doi: 10.1111/gcb.14656

132. Stoor JPA, Berntsen G, Hjelmeland H, Silviken A. "If you do not birget [manage] then you don't belong here": a qualitative focus group study on the cultural meanings of suicide among Indigenous Sámi in arctic Norway. Int $J$ Circumpol Health (2019) 78:1-10. doi: 10.1080/22423982.2019.1565861 
133. Nesbitt L, Meitner MJ, Girling C, Sheppard SRJ, Lu Y. Who has access to urban vegetation? A spatial analysis of distributional green equity in 10 US cities. Landscape Urban Plann (2019) 181:51-79. doi: 10.1016/j.landurbplan.2018.08.007

134. O’Callaghan-Gordo C, Kogevinas M, Cirach M, Castaño-Vinyals G, Aragonés N, et al. Residential proximity to green spaces and breast cancer risk: The multicase-control study in Spain (MCC-Spain). Int J Hyg Environ Health (2018) 221:1097-106. doi: 10.1016/j.ijheh.2018.07.014

135. Mullenbach LE, Mowen AJ, Baker BL. Assessing the Relationship Between a Composite Score of Urban Park Quality and Health. Orig Res (2018) 15:180033. doi: $10.5888 /$ pcd15.180033

136. Flouri E, Papachristou E, Midouhas E. The role of neighbourhood greenspace in children's spatial working memory. Br J Educ Psychol (2018) 89:359-73. doi: 10.1111/bjep.12243

137. Engemann K, Pedersen CB, Arge L, Tsirogiannis C, Mortensen PB, Svenning JC. Residential green space in childhood is associated with lower risk of psychiatric disorders from adolescence into adulthood. PNAS (2019) 116:5188-193. doi: 10.1073/pnas.1807504116

138. Weimann H, Rylander L, Albin M, Skärbäck E, Grahn P, Östergren PO, et al. Effects of changing exposure to neighbourhood greenness on general and mental health: A longitudinal study. Health Place (2015) 33:8-56. doi: 10.1016/j.healthplace.2015.02.003

139. Albrecht G, Sartore GM, Connor L, Higginbotham N, Freeman S, Kelly B, et al. Solastalgia: the distress caused by environmental change. Australas Psychiatry (2007) 15:595-8. doi: 10.1080/10398560701701288

140. Helm SV, Pollitt A, Barnett MA, Curran MA, Craig ZR. Differentiating environmental concern in the context of psychological adaption to climate change. Global Environ Change (2018) 48:158-67. doi: 10.1016/ j.gloenvcha.2017.11.012

141. Fountoulakis KN, Chatzikosta I, Pastiadis K, Zanis P, Kawohl W, Kerkhof AJ, et al. Relationship of suicide rates with climate and economic variables in Europe during 2000-2012. Ann Gen Psychiatry (2016) 15:1-6. doi: 10.1186/s12991-016-0106-2

142. Obschonka M, Stuetzer M, Rentfrow PJ, Shaw-Taylor L, Satchell M, Silbereisen RK, et al. In the shadow of coal: How large-scale industries contributed to present-day regional differences in personality and well-being. J Pers Soc Psychol (2018) 115:903-27. doi: 10.1037/pspp0000175

143. Stanford's School of Earth, Energy \& Environmental Sciences. Climate change has worsened global economic inequality. In: Science Daily. (2019). [Cited: June 22, 2019.] https://www.sciencedaily.com/releases/2019/04/190422151017.htm.

144. Cianconi P, Lesmana CBJ, Ventriglio A, Janiri L. Mental health issues among indigenous communities and the role of traditional medicine. Int J Soc Psychiatry (2019) 65:289-99. doi: 10.1177/0020764019840060

145. Furberg M, Evengård B, Nilsson M. Facing the limit of resilience: Perceptions of climate change among reindeer herding Sami in Sweden. Glob Health Action (2011) 4:1-11. doi: 10.3402/gha.v4i0.8417

146. Bowles DC. Climate Change and Health Adaptation: Consequences for Indigenous Physical and Mental Health. Ann Glob Health (2015) 81:42731. doi: 10.1016/j.aogh.2015.06.004

147. Krakoff S. American Indians, Climate Change and Ethics for a Warming World. Denver Univ Law Rev (2011) 85:1-33.

148. Chavan P, Warren J, Brubaker M, Berner J. Integration, Synthesis, and Assessment of Climate Change Health Impacts for Alaskan Native Communities. Conf Paper (2013). doi: 10.1061/9780784412978.007

149. Petrasek MacDonald J, Cunsolo Willox A, Ford JD, Shiwak I, Wood M. Team, IMHACC e Government., Rigolet Inuit Community. Protective Factors For Mental Health And Well-Being In A Changing Climate:
Perspectives From Inuit Youth In Nunatsiavut, Labrador. Soc Sci Med (2015) 141:133-41. doi: 10.1016/j.socscimed.2015.07.017

150. Compton MT, Shim RS. The Social Determinants of Mental Health. Psychiatric Annals. (2014) 44(1): 17-20 doi: 10.3928/00485713-20140108-03

151. Schwerdtle P, Bowen K, McMichael C. The health impacts of climate-related migration. BMC Med (2017) 16:1-7. doi: 10.1186/s12916-017-0981-7

152. Nath PK, Behera B. A critical review of impact of and adaptation to to climate change in developed and developing economies. Environ Dev Sustain (2011) 13:141-62. doi: 10.1007/s10668-010-9253-9

153. Gifford E, Gifford R. The largely unacknowledged impact of climate change on mental health. Bull Atomic Sci (2016) 72:292-7. doi: 10.1080/ 00963402.2016.1216505

154. Deaton J. Climate change is creating a new kind of grief, and we're completely unprepared for it. Quartz (2018). [Cited: 25 May, 2019.] https://qz.com/1306707/ uncovering-the-mental-health-crisis-of-climate-change/

155. APA. Diagnostic and Statistical Manual of Mental Disorders, Fifth Edition. Arlington, VA: American Psychiatric Association (2013).

156. Fritze JG, Blashki GA, Burke S, Wiseman J. Hope, despair and transformation: Climate change and the promotion of mental health and wellbeing. Int J Ment Health Syst (2008) 2:1-10. doi: 10.1186/1752-4458-2-13

157. Howell J, Elliott JR. Damages Done: The Longitudinal Impacts of Natural Hazards on Wealth Inequality in the United States. Soc Probl (2018) 66:44867. doi: 10.1093/socpro/spy016

158. Janiri L, Spinetti G, Mazza M, Di Nicola M. Meteoropathy: a new disease. Adv In Psychiatry (2009) III:45-52.

159. Mazza M, Di Nicola M, Catalano V, Callea A, Martinotti G, Harnic D, et al. Description and validation of a questionnaire for the detection of meteoropathy and meteorosensitivity: the METEO-Q. Compr Psychiatry (2012) 53:103-6. doi: 10.1016/j.comppsych.2011.02.002

160. Santiago PN, McLay RN, Hammer PS. Meteorologic Factors in Emergency Evaluation, Admission, and Discharge. Psychiatr Serv (2005) 56:1625. doi: 10.1176/appi.ps.56.12.1625

161. Translated by W.H.S Jones. Hippocrates, Ancient Medicine, Volume I. Cambridge, Masschusetts, USA (1923).

162. Torres JM, Casey JA. The centrality of social ties to climate migration and mental health. BMC Public Health (2017) 17:1-10. doi: 10.1186/s12889-017-4508-0

163. Valois P, Caron M, Gousse-Lessard AS, Talbot D, Renaud JS. Development and validation of five behavioral indices of flood adaptation. BMC Public Health (2019) 19:245. doi: 10.1186/s12889-019-6564-0

164. Marshall NA, Park SE, Adger WN, Brown K, Howden SM. Transformational capacity and the influence of place and identity. Environ Res Lett (2012) 7:19. doi: 10.1088/1748-9326/7/3/034022

165. Woodbury Z. Climate Trauma: Toward a New Taxonomy of Trauma. Ecopsychology (2019) 11:1-8. doi: 10.1089/eco.2018.0021

Conflict of Interest: The authors declare that the research was conducted in the absence of any commercial or financial relationships that could be construed as a potential conflict of interest.

Copyright (c) 2020 Cianconi, Betrò and Janiri. This is an open-access article distributed under the terms of the Creative Commons Attribution License (CC BY). The use, distribution or reproduction in other forums is permitted, provided the original author(s) and the copyright owner(s) are credited and that the original publication in this journal is cited, in accordance with accepted academic practice. No use, distribution or reproduction is permitted which does not comply with these terms. 